The Agriculturists 18(1):144-163(2020) ISSN 2304-7321 (Online), ISSN 1729-5211 (Print)

A Scientific Journal of Krishi Foundation

Indexed Journal

DOI: https://doi.org/10.3329/agric.v18i1.49467

Review Article

\title{
Reactive Nitrogen in Crop, Fishery and Livestock Sectors of Bangladesh
}

\author{
Md. Mizanur Rahman ${ }^{1}$ and Jatish Chandra Biswas ${ }^{2}$ \\ ${ }^{I}$ Dept. of Soil Science, Bangabandhu Sheikh Mujibur Rahman Agricultural University, Gazipur 1706, \\ Bangladesh; ${ }^{2}$ Soil Science Division, Bangladesh Rice Research Institute, Gazipur 1701, Bangladesh \\ *Corresponding author and Email: mizan@bsmrau.edu.bd
}

Received: 29 September 2019

Accepted: 25 June 2020

\begin{abstract}
Agriculture in Bangladesh is characterized by crop, fishery and livestock sectors. Urea- $\mathrm{N}$ is used in all three sectors. Crop sector plays a dominant role in urea consumption to supply of food for ever burgeoning population. Application of inorganic $\mathrm{N}$ fertilizer definitely increased agricultural productivity. This however playing a significant role in altering global nutrient budget, water quality, greenhouse gas emission, and ultimately affecting the global climate. Though cropping intensity and use of $\mathrm{N}$ fertilizer have increased, yield plateauing is a concern for food security. Recovery efficiency of $\mathrm{N}$ rarely exceeds $30 \%$ in both crop and fish culture, while remaining reactive $\mathrm{N}$ is a global concern. Different industries have emerged in the last decade producing huge amounts of effluents discharging to the environment without treatment which appeared as a potential threat in damaging and disintegrating the environment. Resultant negative effect from application of large amount of organic and inorganic fertilizers and feeds in fishponds is a matter of boundless anxiety as it might act as a source of reactive $\mathrm{N}$. Livestock sector comprising poultry and dairy produce huge amount of manure annually which is equivalent to 0.30 million tons of $\mathrm{N}$ and because of poor manure management reactive $\mathrm{N}$ is spreading in the environment. Reluctant attitudes on these crucial issues might bring a disaster through stopping natural ecosystem functions of the environment from where ' $U$ ' turn will rather be impossible. Adoption of resource conservation strategies, judicial and optimum use of $\mathrm{N}$ fertilizers in all agricultural sectors, improved management of livestock manure and industrial effluents are strongly recommended for environmental sustainability.
\end{abstract}

Keywords: Urea fertilizer, industrial effluents, manure, environment

\section{Introduction}

Nitrogen $(\mathrm{N})$ is an essential nutrient element. It is required for all life forms on earth which remains in plentiful in the atmosphere. But atmospheric $\mathrm{N}$ is unusable by most of the organism. It is transformed into reactive forms $(\mathrm{Nr})$ of $\mathrm{NH}_{3}, \mathrm{NO}_{3}, \mathrm{NOx}, \mathrm{N}_{2} \mathrm{O}$, amines and other organic forms of $\mathrm{N}$ (Erisman et al., 2011). The $\mathrm{Nr}$ in the environment is produced naturally mainly by lightning, wildfires and biological (BNF) $\mathrm{N}_{2}$ fixation. The $\mathrm{Nr}$ is also produced through burning of fossil fuels which leads to the formation of nitrogen oxides (NOx) in the atmosphere. It is reported that in the last 150 years, the annual release of $\mathrm{Nr}$ from agricultural, industrial and transportation sectors to the earth's atmosphere, soils, and water bodies have increased by ten folds (UNEP and WHRC, 
2007). A substantial amount of $\mathrm{N}$ is fixed in soil through different natural processes which is not adequate to produce more crop yields from limited land resource. Use of synthetic $\mathrm{N}$ fertilizer definitely increased agricultural productivity, which however playing significant role in altering global nutrient budget, soil and water quality, greenhouse gas (GHG) emission, and ultimately contributing towards the global climate change (Lu and Tian, 2017).

Agriculture is the driving force of economy of Bangladesh. It contributes about $21 \%$ to the country's GDP (AIS, 2016). On the other hand, the country appeared as one of the most climate vulnerable countries in the world. Fig. 1 evinced that because of application of nitrogen fertilizers GHGs are released from crop field to the atmosphere. Therefore, to increase production from all agricultural sectors under changing climate has become a great challenge in Bangladesh.

About 87000 hectares of agricultural land is lost every year because new settlements, industrialization, roads, and other development works, therefore a tremendous pressure is exerted on limited land resource to get more foods for increased population. Therefore, for increasing production reactive nitrogen in the form of synthetic fertilizers is largely used in different sectors of agriculture including crop, fisheries, livestock \& poultry. Obviously, because of intensive cultivation using solely inorganic fertilizers food production has become stagnant in most of the cases and soil health degraded.

There is no proper databases/statistics on how much inorganic and organic $\mathrm{N}$ fertilizer are used in different sectors of agriculture, their use efficiencies and possible distribution in the environment. Therefore, the present study is aimed to present scenarios of $\mathrm{N}$ fertilizers use in crop, fisheries and livestock sectors in Bangladesh that might help policy makers for better understanding and policy formulation in this very crucial concern.

\section{Soil fertility status, nitrogenous fertilizer consumption and production in Bangladesh}

Bangladesh is a land of rivers and a huge amount of silt deposits every year in the floodplain $(80 \%$ of the country's area) carried by different rivers and their tributaries. Therefore, traditionally the soil of Bangladesh is fertile. Nitrogen, phosphorus, potassium and sulphur are the most commonly deficient nutrients in the soils of Bangladesh, while zinc deficiency is widespread in calcareous and light textured soils and boron deficiency is also being observed in sandy and alkaline soils (FRG, 2012). The use of inorganic fertilizers, irrigation water and improved \& high yielding crop varieties in agriculture until 1930 was almost unknown.

A number of earlier scientific reports extracted from several nutrient experiments conducted in different research stations showed insignificant crop response on soil fertility. Soil fertility has been started to be a concern of scientists of Bangladesh since late fifties. Nitrogen deficiency was identified in 1951 in Bangladesh and then gradually P (1957), K (1960), S (1980) and Zn (1982) for rice cultivation. Inorganic fertilizer was first introduced in Bangladesh in the year of 1949-1950 with the import of only 2600 MT of ammonium sulfate (Kafiluddin, 2008). Since then, fertilizer use in the country is gradually and progressively increasing as the country has been modernizing its agriculture for increasing food production and attaining food self-sufficiency. The share of inherent soil nutrients in crop production is decreasing, while the contribution of inorganic fertilizers is increasing since 1985 to 2007 (Fig. 2).

The green revolution for increasing food grain production in Bangladesh started with the introduction of IR8 rice variety from IRRI, Philippines in 1967. The spread of green revolution and the resulting increase in food production was visible after the country's independence in 1972. 

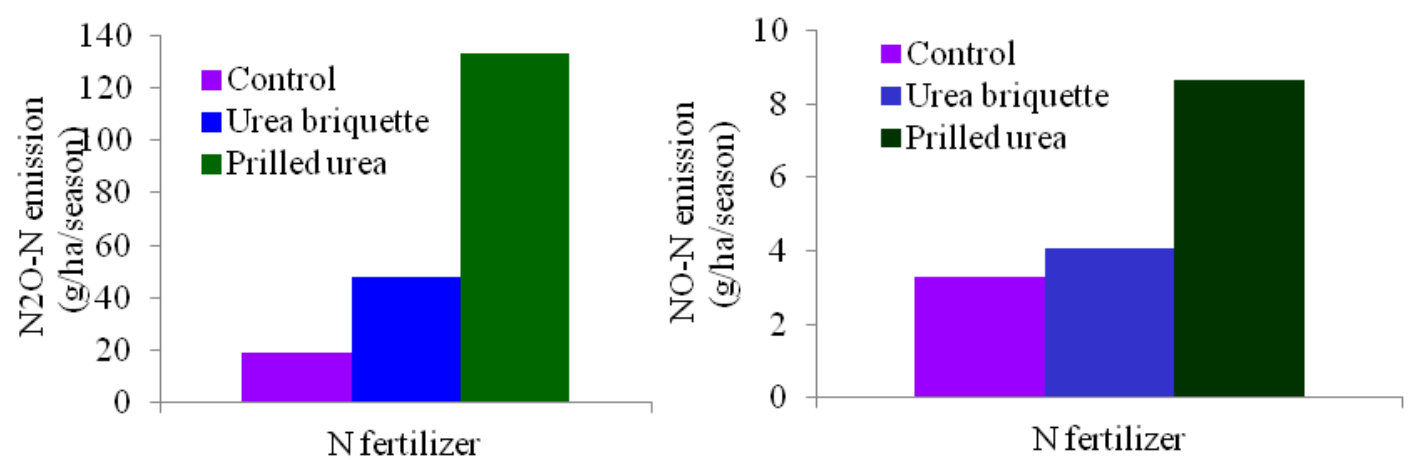

Figure 1. Nitrous and nitric oxide emissions from Boro rice field in Bangladesh as affected by different forms of $\mathrm{N}$ fertilizer application (Gaihre et al., 2018)

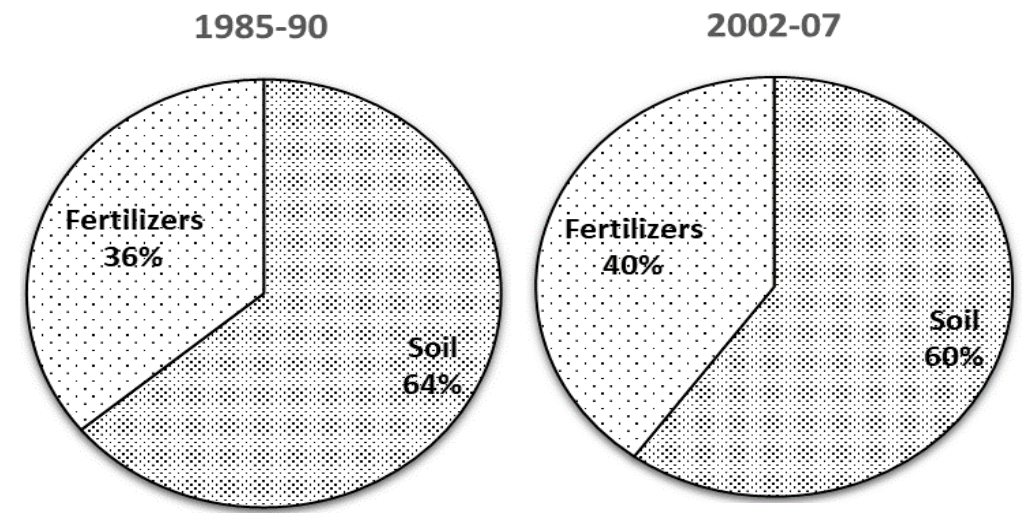

Figure 2. Contribution of soil and fertilizer in terms of nutrient supply to rice production (Shah et al., 2008)

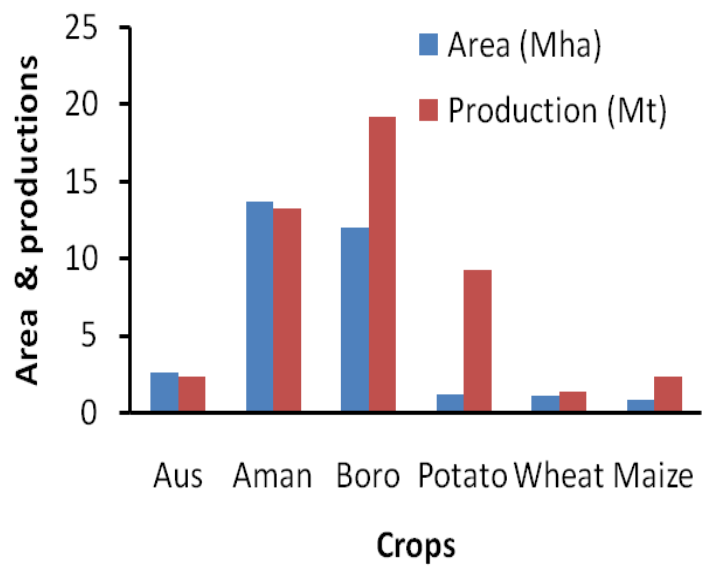

Figure 3. Crop statistics of Bangladesh (BBS, 2015)

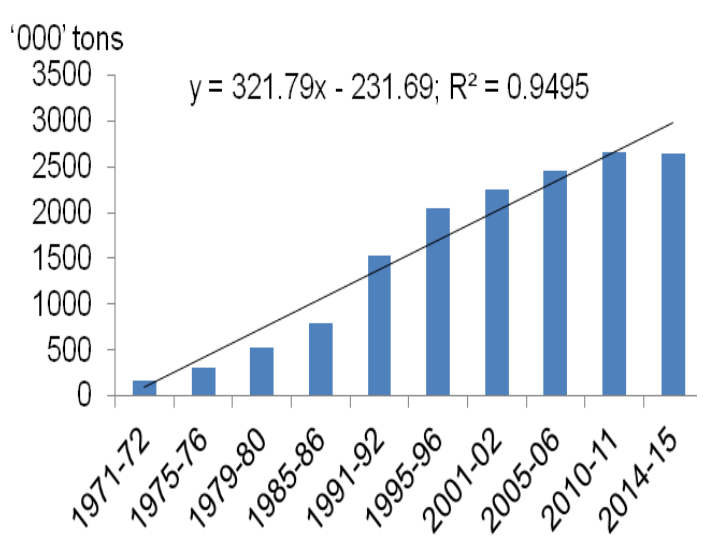

Figure 4. Urea consumption in Bangladesh (BBS, 1980; FRG, 2012; AIS, 
During independence the population of Bangladesh was only 75 million, in 1980 increased to 81.36 million, while the current population of Bangladesh is 166.01 million (World Population Review, 2018). In 1980-81, the food grain production was only 15 million tons and in 2014-15, it increased to over 36 million tons (The Daily Star, November 14, 2014; AIS, 2016) indicating a significant positive effect of modern technologies in agriculture of Bangladesh. Area coverage and production of rice, wheat, maize and potato in 2015 in Bangladesh indicated the maximum utilization of our agricultural land which ultimately contributed to a significant increase in crop yields (Fig. 3) and furthermore indicated the resultant increase in urea use (Fig. 4).

To increase food production, cropping has been intensified with high yielding modern varieties that consume huge amounts of inorganic fertilizers. At present, N constitutes about 55\% of the total nutrients used in Bangladesh (BFA, 2018). From the Fig. 4 it is observed that in 1971-72 consumption of urea was only 170,000 tons, which has increased to about three million tons (mt) in 2014-15 (BBS, 1980; FRG, 2012; AIS, 2016). Bangladesh Chemical Industries Corporation (BCIC) operates six urea fertilizers (Table 1), one ammonium sulfate and two DAP plants to meet up the fertilizer demand in the country. Karnaphuli Fertilizer Co Ltd (KAFCO) produces urea fertilizer and extra ammonia product for domestic use and export. Different urea manufacturing plants of Bangladesh launched at different times have the productive capacity of 2.76 million tons (Table 1), which may fulfill urea demand however, because of technical efficiency and less supply of natural gas the plants could not achieve the targets of production. Therefore, a significant amount of urea fertilizer needs to be imported every year (Fig. 5). The total installed capacity for ammonia is 1.88 million tons per year. The lone ammonium sulfate plant has installed capacity of 10,000 tons ammonium sulfate per year. The two DAP plants based on local ammonia and imported phosphoric acid has the capacity of 489,600 tons DAP per year equivalent to 191,144 tons urea. Use of DAP was only 38000 tons during 1978-79 which increased rapidly in recent years (Fig. 6). The use of DAP is also mostly for crop production, although both urea and DAP are also used in poultry and livestock sectors.

Rice is the staple food of the population of Bangladesh and this main crop consumes a large amount of urea fertilizer which must needs to be further increased in future to meet up the food demand of our increased population. The United Nation has estimated that the total population of Bangladesh will be 194.35 million in 2050, when the total rice demand will be 49.07 million tons which is 30 per cent higher than the total rice production in 2013-14 and accordingly urea demand will be increased to produce the increased rice grain (The Daily Observer, 2015).

Table 1. Urea manufacturing plants in Bangladesh

\begin{tabular}{lccc}
\hline Factory name & Initiation & $\begin{array}{c}\text { Production } \\
\text { capacity (t/year) }\end{array}$ & $\begin{array}{c}\text { Natural gas consumption } \\
\text { (MSCF/t urea) }\end{array}$ \\
\hline Natural Gas Fertilizer Factory & 1961 & 106000 & 59.0 \\
Urea Fertilizer Factory Ltd & 1970 & 340000 & 35.2 \\
Zia Fertilizer Co Ltd & 1981 & 528000 & 28.0 \\
Polash Urea Fertilizer Factory & 1986 & 95000 & 49.9 \\
Jamuna Fertilizer Co Ltd & 1987 & 561000 & 27.5 \\
Chittagong Urea Fertilizer Ltd & 1991 & 561000 & 24.4 \\
Karnaphuli Fertilizer Co Ltd & 1994 & 575425 & 23.2 \\
\hline Total & - & 2766425 & - \\
\hline
\end{tabular}




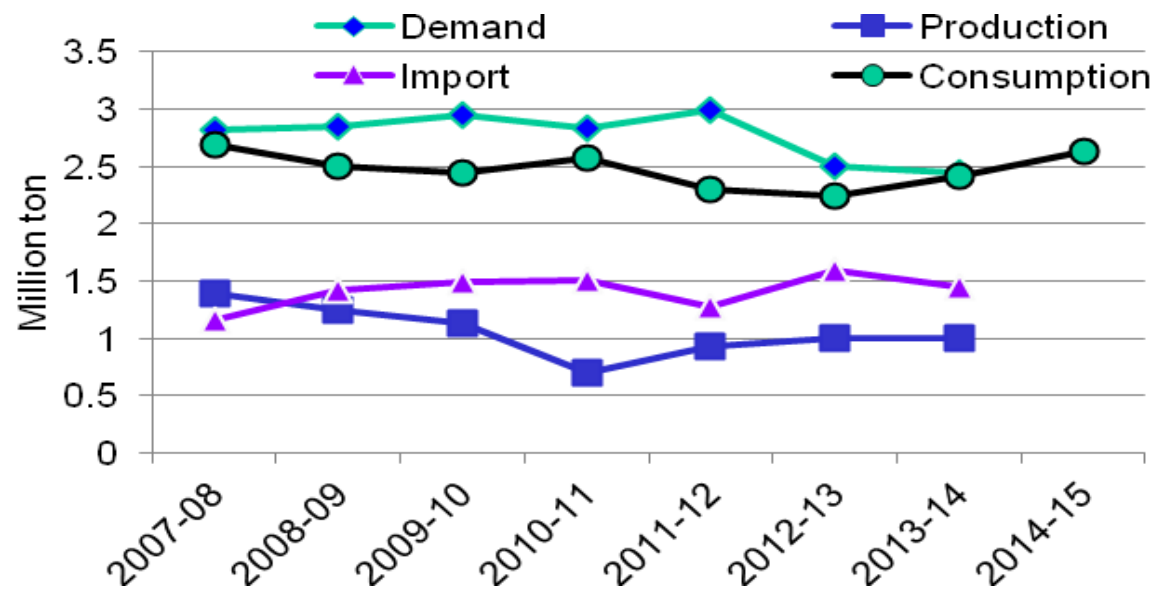

Figure 5. Urea production, demand, import and consumption in Bangladesh (Source: Bangladesh Fertilizer Association)

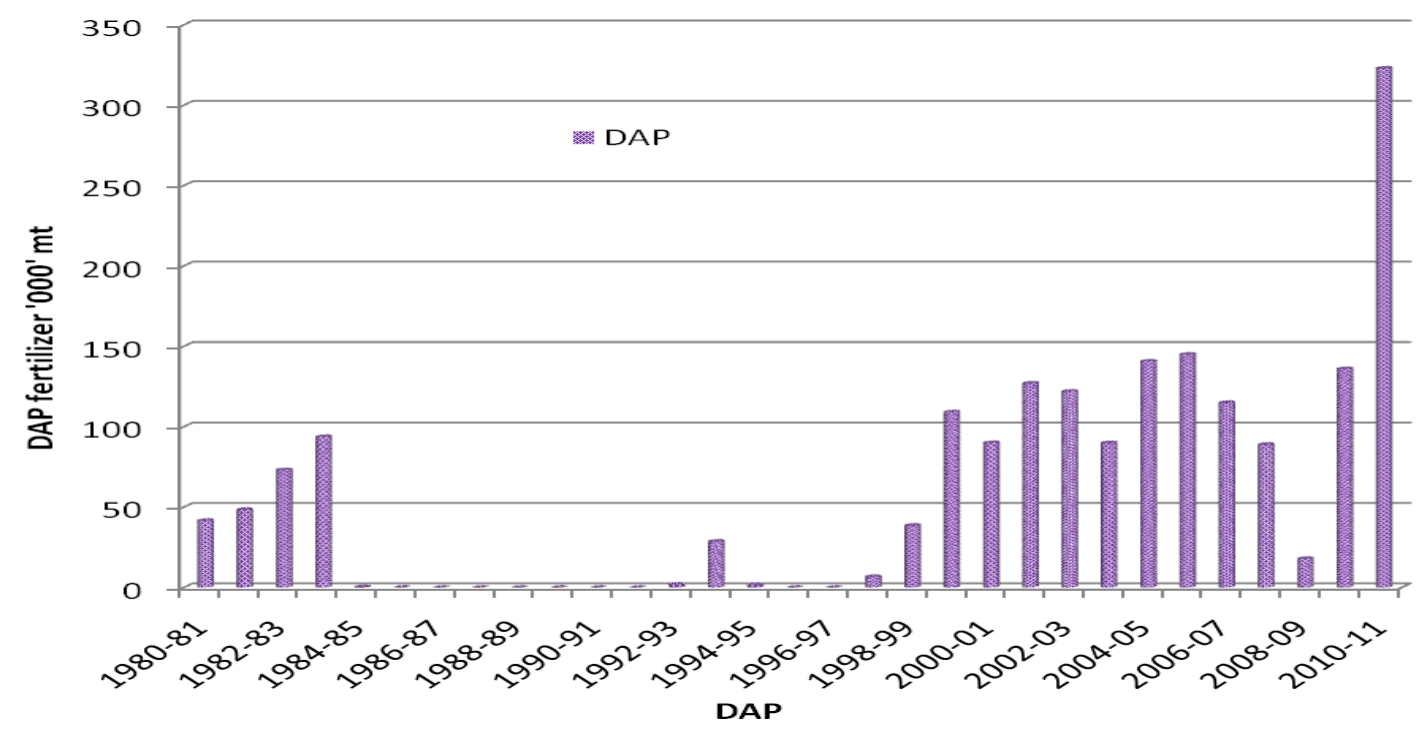

Figure 6. Trend in DAP fertilizer use in Bangladesh (FRG, 2012)

According to Bangladesh Unnayan Onneshan, the present requirement of urea for rice crop is 2.45 million tons, while in 2050 the projected urea fertilizer requirement will be 3.92 million tons (Fig. 8). Among three types of rice, urea consumption is the lowest in aus rice while the highest in boro rice. The demand of fertilizers is not only increasing in Bangladesh it is also increasing globally. The global potential nitrogen balance as a percentage of $\mathrm{N}$ fertilizer demand is expected to steadily rise during the forecast period from $3.7 \%$ in 2014 to $5.4 \%$ in 2015 and then $6.9 \%$ in 2016, a further $8.8 \%$ in 2017 and reach $9.5 \%$ in 2018 (FAO, 2015).

Inorganic nitrogen fertilizer production in the Haber-Bosch process in the early $20^{\text {th }}$ century has converted a large amount of unreactive $\mathrm{N}$ to 
reactive forms (Galloway et al., 2004). During the green revolution the dramatic growth in inorganic fertilizer production and application to crop fields has contributed greatly in increasing agricultural productivity and thus ensured food security for the ever burgeoning global population (Erisman et al., 2008). However, excessive use of inorganic fertilizer in agriculture accompanied so many environmental and ecological problems and threatened the sustainability in producing food and energy (Ju et al., 2009; Sutton et al., 2011; Lu and Tian, 2013).

\section{Use efficiency and loss of nitrogen}

Nitrogen content in most of the soils of Bangladesh is low to medium. Therefore, a large amount of synthetic $\mathrm{N}$ fertilizers are applied to soils to increase crop production and provide food for the increasing population. Though cropping intensity and use of $\mathrm{N}$ have increased, yield plateau is a concern for food security in future Bangladesh. Nitrogen is the most limiting plant nutrient in almost all production environments. Very little amount of mineral nitrogen i.e. ammonium nitrogen $\left(\mathrm{NH}_{4}{ }^{+}-\mathrm{N}\right)$ and nitrate nitrogen $\left(\mathrm{NO}_{3}{ }^{-} \mathrm{N}\right)$ present in agricultural soils. Nitrogen goes through many changes in the soil and environment and increased its removal from the production environment (Weil and Brady, 2016).

The loss of nitrogen from agricultural lands is very high in the tropical and subtropical countries like Bangladesh. Therefore, efficiencies of $\mathrm{N}$ fertilizer application have decreased. Because of intensive cropping with modern crop varieties and use of sole inorganic fertilizers, nutrient use efficiency in Bangladesh has declined. Moreover, contribution of soil for crop productivity is also declining. As a result, more $\mathrm{N}$ has to be used in future to get almost similar rice grain yield of present condition. Application of inorganic $\mathrm{N}$ fertilizer in agriculture needs to be continued as an indispensable activity for meeting global food, feed, and fiber needs (Wortmann et al., 2011). At the same time, its efficiency also needs to be increased adopting different soil and crop management activities. In the research stations of Bangladesh, the apparent recovery efficiencies of $\mathrm{N}$ for our major crops viz. rice, wheat, maize and potato are 48, 62, 26 and $58 \%$, respectively and agronomic efficiencies are 37, 40, 17 and 110 $\mathrm{kg} / \mathrm{kg}$, respectively (Fig. 8), which are much lower in the farmers' fields.

Higher rates of $\mathrm{N}$ fertilizer application in recent years have increased its losses through different ways which include immobilization, mineralization, nitrification, denitrification, fixation, and translocation and are lost from crop fields mainly through surface run-off, leaching in the soil profile, ammonia volatilization and denitrification. Leaching loss of $\mathrm{N}$ occurs in the form of $\mathrm{NO}_{3}{ }^{-}$and $\mathrm{NH}_{4}{ }^{+}$from rice fields and the extent of loss as $\mathrm{NO}_{3}^{-}-\mathrm{N}$ is more than $90 \%$, while $\mathrm{NH}_{3}$ volatilization loss ranged from $4-6 \%$ of the applied N (Weil and Brady, 2016). Ammonium and nitrate leaching loss from paddy soils under different leaching periods are shown in the Table 2. $\mathrm{NH}_{4}{ }^{+}-\mathrm{N}$ loss is higher than $\mathrm{NO}_{3}{ }^{-}-\mathrm{N}$ loss in wet land paddy field (Islam et al., 2014).

Significant proportions of $\mathrm{N}$ applied for rice production is also lost as $\mathrm{N}_{2} \mathrm{O}, \mathrm{NO}$ and $\mathrm{NH}_{3}$ from crop fields especially when prilled urea is used (Fig. 1 and 9). According to Bangladesh Rice Research Institute, application of urea super granule can increase production of rice by $15-20$ $\%$ and decreased urea application by $20-30 \%$. Moreover, use of urea briquette significantly reduces $\mathrm{N}_{2} \mathrm{O}$ and $\mathrm{NO}$ emission and $\mathrm{NH}_{3}$ volatilization loss from rice field. Deep placement of prilled urea by applicator is also showing promising performances in rice. We need to develop and use bio-organic fertilizers for increased efficiency of $\mathrm{N}$ and reduction of $\mathrm{N}$ fertilizer use for crop production. 


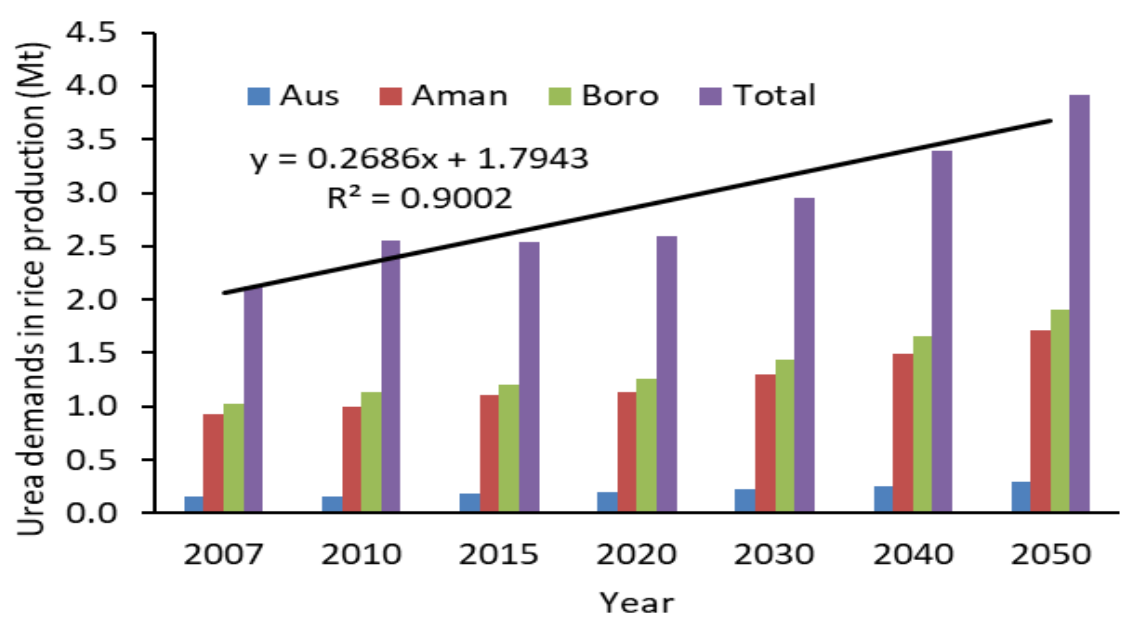

Figure 7. Present and future demand of urea fertilizer in rice production of Bangladesh (Produced using data from FRG, 2012; AIS 2016; BBS, 2016; Bangladesh Unnayan Onneshan)

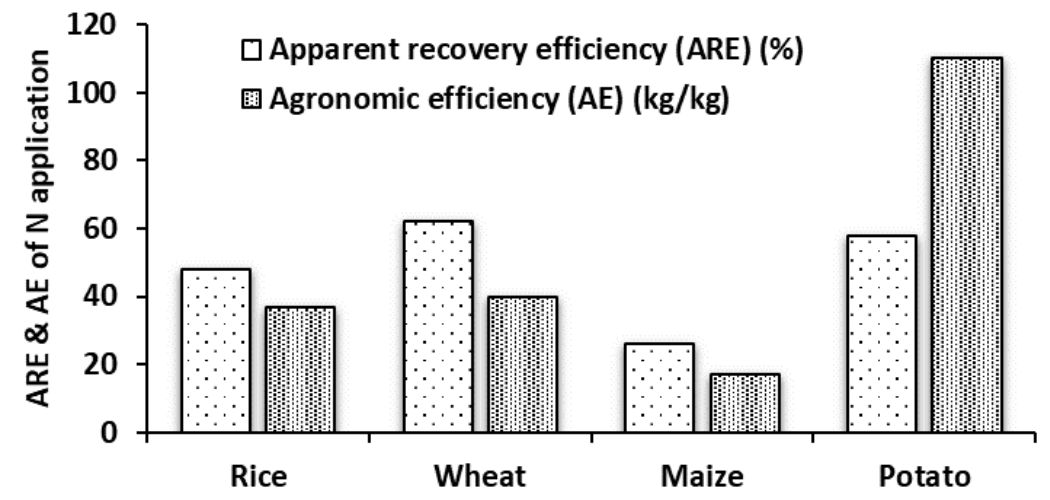

Figure 8. Apparent recovery and agronomic efficiencies of $\mathrm{N}$ fertilizer in major crops of Bangladesh (Department of Soil Science, BSMRAU, unpublished)

Table 2. Leaching loss of $\mathrm{N}$ from agricultural field under continuous standing water condition (Islam et al., 2014)

\begin{tabular}{lcccc}
\hline Leaching periods (days) & \multicolumn{2}{c}{$\mathrm{NH}_{4}-\mathrm{N}$ loss $(\mathrm{kg} / \mathrm{ha})$} & \multicolumn{2}{c}{$\mathrm{NO}_{3}$-N loss $(\mathrm{kg} / \mathrm{ha})$} \\
\cline { 2 - 5 } & $\mathrm{N}$ applied @ $120 \mathrm{~kg} / \mathrm{ha}$ & $\mathrm{N}_{0}$ & $\mathrm{~N}$ applied @ 120 kg/ha & $\mathrm{N}_{0}$ \\
\hline $1-15$ & 11.63 & 3.88 & 2.84 & 1.29 \\
$16-30$ & 9.54 & 3.18 & 2.27 & 0.91 \\
$31-45$ & 8.38 & 2.56 & 2.17 & 0.69 \\
$46-60$ & 8.54 & 2.67 & 2.13 & 0.64 \\
$61-75$ & 9.88 & 2.65 & 2.65 & 0.6 \\
$76-90$ & 9.72 & 2.63 & 2.36 & 0.53 \\
\hline
\end{tabular}



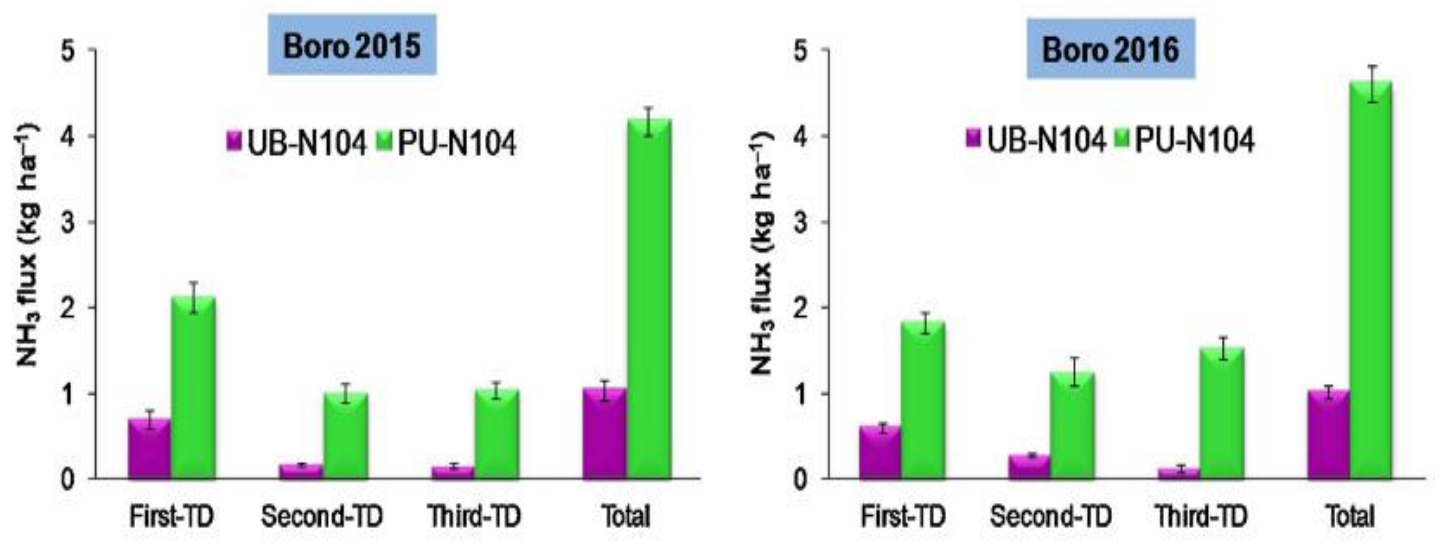

Figure 9. Loss of $\mathrm{N}$ as $\mathrm{NH}_{3}$ from Boro rice field as influenced by urea briquette (UB) and prilled urea (PU) application (Islam et al., 2018); TD = top dressing of urea

\section{Nitrogen loading in soil from different industrial effluents in Bangladesh}

The industrial sector in Bangladesh has been a significant contributor to the country's economy where its share to GDP in 2011 standing at 28.6\% (Paul et al., 2013). Although Bangladesh is an agro-based country, the industrial sector of the country is also developing with a considerable growth rate where textile industry is dominating. The number of textiles (except handloom), tanneries (operated), pharmaceuticals and sugar mills are 10416, 113, 20 and 15 , respectively. Tanneries though are in small number compared to textiles however, their effects are very serious in damaging and polluting the environment. Different industries have emerged in the last decade in Bangladesh producing huge amounts of effluents, which are directly discharged to the environment without any treatment (Saha, 2007). Industrial effluent containing reactive nitrogen and different heavy metals is a serious threat to human, plant, aquatic lives and ultimately to the total ecosystems. Release of untreated effluents to the environment is of great concern for the sustainable use of natural resources like soil and water which become degraded and creates negative impacts on crops, insect pests, and animal and human lives (Hossain et al., 2010; Eruola et al., 2011).
According to Paul et al. (2013) most of the tanneries in Bangladesh everyday generate $20000 \mathrm{~m}^{3}$ effluent and 232 tons solid waste and they do not operate effluent treatment plants disobeying the government rules. Thus tanneries discharged huge amount of untreated effluents to the environment even though both liquid and solid wastes are a potential pollutant. Textile industries consume huge volume of water and accordingly create huge amount of effluent (Table 3). Textile industries produce effluents through sizing, desizing, scouring, bleaching, mercerizing, dyeing, printing and finishing. Dey and Islam (2015) reported that in wet processing commonly $1 \mathrm{~kg}$ fabric needs $120 \mathrm{~L}$ water for complete textile processing.

It is also estimated by them that $12-65 \mathrm{~L}$ of water is required for processing one meter of cloth. Therefore, it is effortlessly agreed that what a large volume of waste water is generated by different textile industries every day in Bangladesh. Waste water, polluted soils, effluents and waste of different industries contain different forms of reactive nitrogen (Table 4). Though data are insufficient, however it gives a glimpse of the potential threat of industrial effluents and wastes in damaging and disintegrating the environment. 
Table 3. Water consumption and effluent generation from textile industries (Dey and Islam, 2015)

\begin{tabular}{lcc}
\hline Production of mill (m/day) & Water consumption (KL/day) & Volume of effluent (KL/day) \\
\hline 220000 & 13870 & 8000 \\
190000 & 2300 & 1900 \\
80000 & 3500 & 3400 \\
45000 & 1830 & 1750 \\
35000 & 1050 & 800 \\
\hline
\end{tabular}

Table. 4. Nitrogen contents in different industrial effluents in Bangladesh

\begin{tabular}{lccccc}
\hline Industry & $\mathrm{TN}$ & $\mathrm{NH}_{4}{ }^{+}$ & $\mathrm{NO}_{3}{ }^{-}$ & $\mathrm{NO}_{2}{ }^{-}$ & Reference \\
\hline Tannery effluent) $(\mathrm{mg} / \mathrm{L})$ & 22.5 & - & 13 & - & Chowdhury et al. 2015 \\
Textile - water $(\mathrm{mg} / \mathrm{L})$ & - & 0.32 & 15.2 & 0.19 & Soil Science, BSMRAU \\
Textile - soil $(\mathrm{mg} / \mathrm{kg})$ & 2600 & - & - & - & Begum et al. 2011 \\
Sugar mill waste water $(\mathrm{mg} / \mathrm{L})$ & - & 0.51 & 19.84 & 0.26 & Tabriz et al. 2011 \\
\hline
\end{tabular}

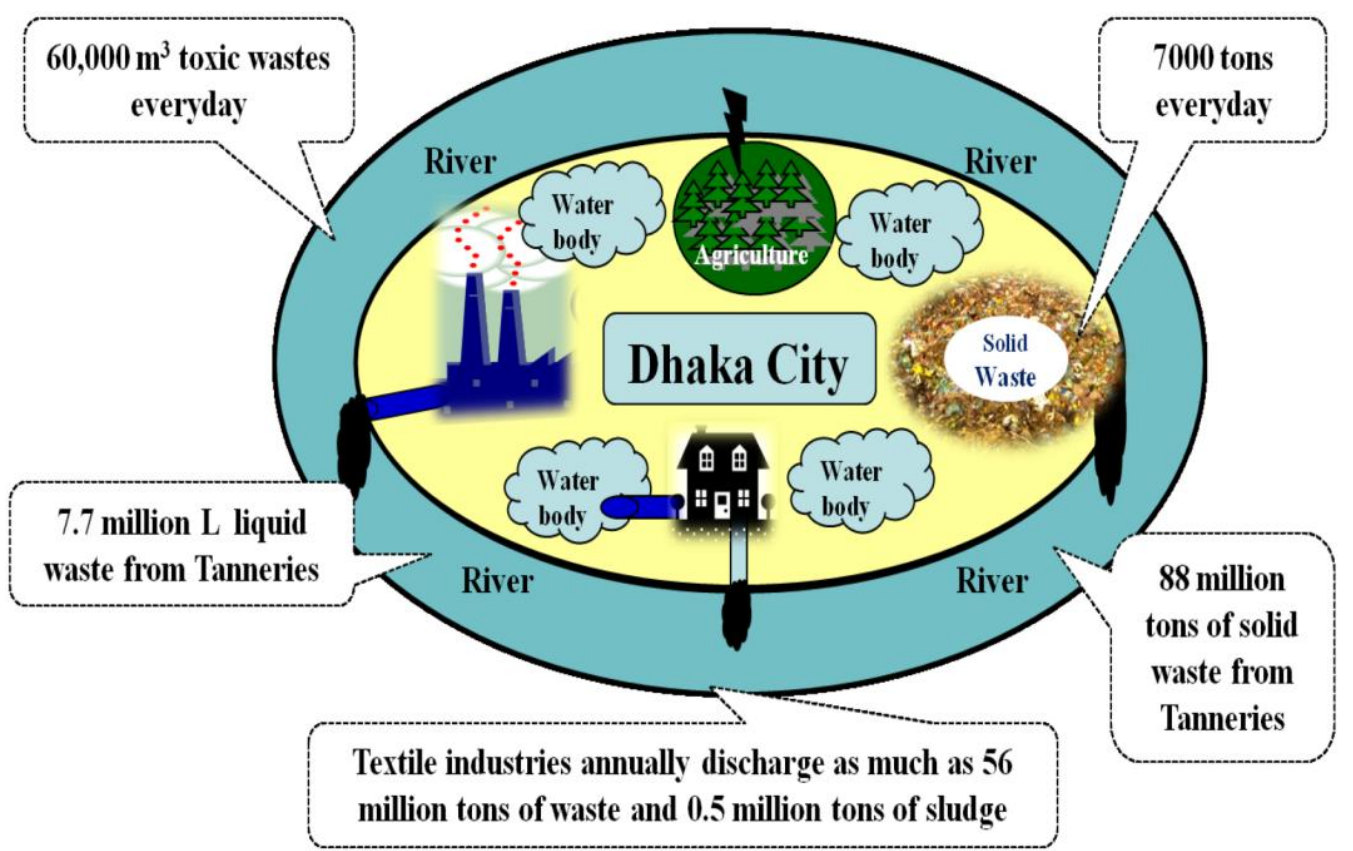

Figure 10. River pollution around Dhaka City from different industrial wastes (Islam et al. 2015)

Industries in Bangladesh are mainly concentrated surrounding the eight divisional cities and other big city corporations viz. Gazipur, Narayanganj.
Dhaka is the mega city and which is also the capital city of Bangladesh produces 7000 tons solid waste everyday (Islam et al., 2015) in 
addition to huge amount of solid and liquid wastes from different textiles and tanneries (Fig. 10). Guha (2011) reported that waste water produced in knit industries is 0.13 million $\mathrm{m}^{3} /$ day, while textile sector discharged effluent is 2 million $\mathrm{m}^{3} /$ day. All these waste materials are directly discharged to four rivers surrounding Dhaka city and these waste materials are potential sources of reactive nitrogen and other nutrients and as well as heavy metals. Though the scenarios are matter of great concerns however, nobody is taking care of the issue. Reluctant attitudes on this very urgent issue might bring a disaster through stopping natural ecosystem functions of the environment from where ' $U$ ' turn will be rather impossible.

\section{Nitrogen use in aquaculture sector of Bangladesh}

Fisheries sector plays a vital role in Bangladesh in terms of supplying over $60 \%$ animal food and contributing $3.8 \%$ to the country's GDP (FAO, 2014a). The country has diverse and extensive fisheries resources comprising capture fishery and aquaculture. Contribution of inland aquaculture in Bangladesh is $83.7 \%$ compared to the total production (Fig. 11) and it is growing very rapidly where during $1984-85$ to $2008-09$

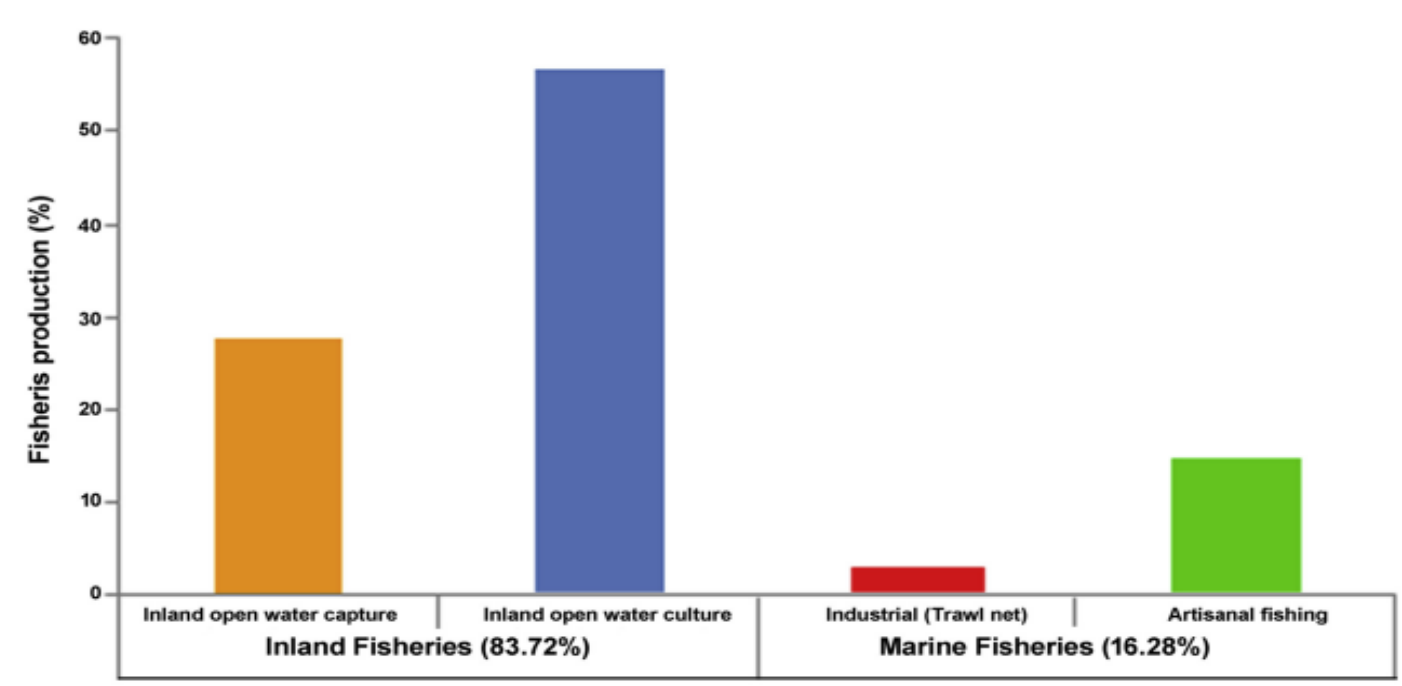

Figure 11. Sector wise fish production in Bangladesh (FRSS, 2016) the growth rate of aquaculture was reported to be over $9 \%$ (DoF, 2010). Bangladesh is the fi fth largest aquaculture producer in the world where the country's farmed fi sh increased 1.4 times from 0.79 million tons in 2001-2002 to 1.9 million tons in 2012-2013 (DoF, 2014; FAO, 2014b). This increased fish production is accompanied by application of large amount production inputs in pond systems. Semiintensive tropical and sub-tropical fish culture is based on the balanced supply of nutrients through fertilization and supplementary feeding. Mamun-Ur-Rashid et al. (2013) reported that production and sale of fish feed in Bangladesh aquaculture has increased radically in the last decade where about 1.04 million tons of feed are produced in commercial factories, and moreover between 0.3 and 0.4 million tons are produced at village level (Fig. 12 \& 13). No doubt, application of improved feeds and fertilizers along with best management approaches has contributed to higher production of major fish species in Bangladesh. Though there is lacking of information on how much inorganic and organic fertilizers are used in in aquaculture in Bangladesh, however, resultant negative effect in the environment from application of large amount of fertilizers and feeds in the fishponds is a matter of great concern. 


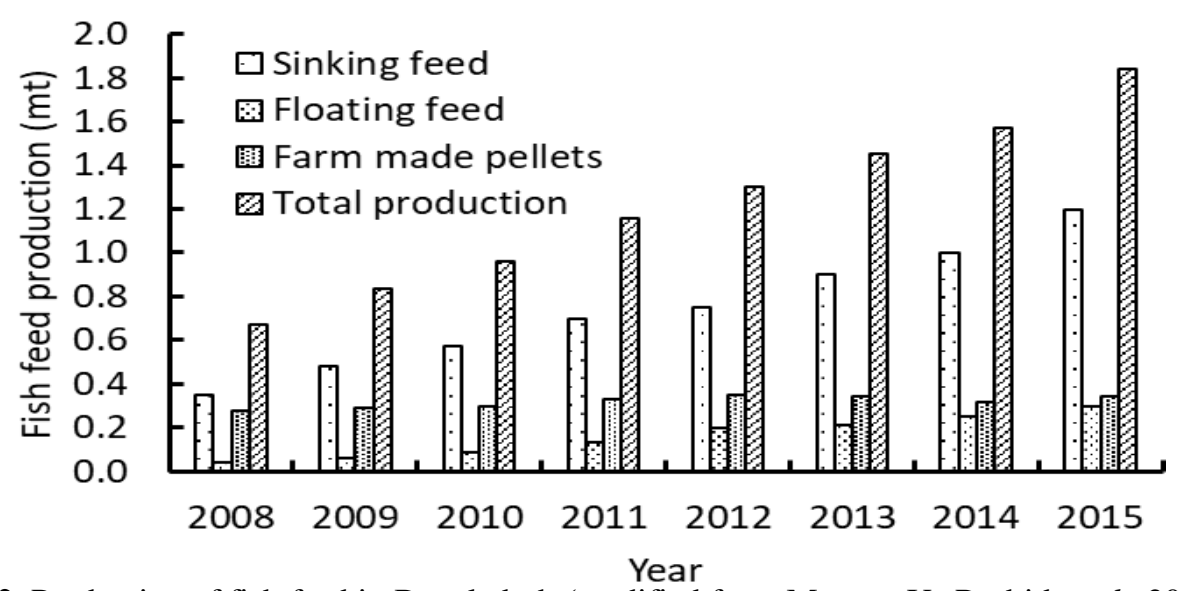

Figure 12. Production of fish feed in Bangladesh (modified from Mamun-Ur-Rashid et al., 2013).

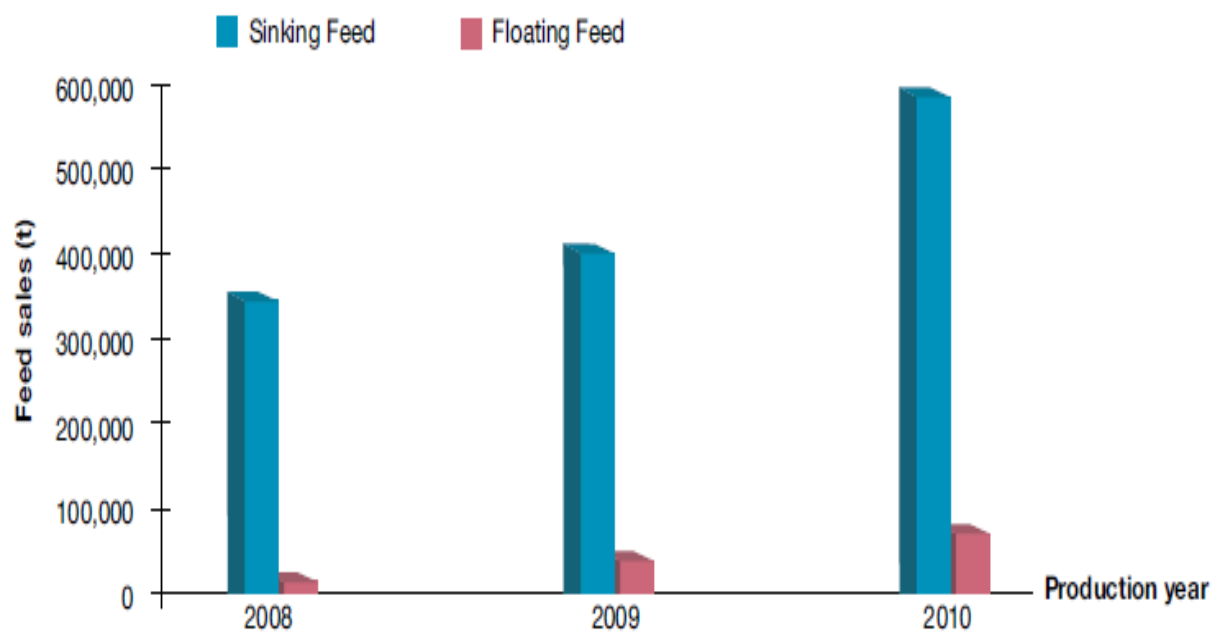

Figure 13. Sales of formulated fish feeds in Bangladesh (Belton et al. 2011)

Table 5. Nitrogen budget in tilapia ponds under different inputs in Bangladesh

\begin{tabular}{lccc}
\hline Parameters & \multicolumn{3}{c}{ N input/outputs in tilapia ponds $(\mathrm{kg})$} \\
\cline { 2 - 4 } Inputs & Urea & Urea + Poultry manure & Feed \\
Fertilizers & 10.00 & 10.00 & 10.00 \\
Feed & - & - & 3.53 \\
Manure & - & 3.22 & - \\
Outputs & & & 2.95 \\
Fish & 0.89 & $\mathbf{1 0 . 9 7}$ & $\mathbf{2 1 . 8 0}$ \\
Recovery (\%) & $\mathbf{8 . 9 0}$ & \multicolumn{2}{c}{$\mathbf{8 0}$} \\
(Source: unpublished data collected from Department of Soil Science, BSMRAU, Bangladesh, 2017)
\end{tabular}


Annual $\mathrm{N}$ inputs applied to fishponds of Bangladesh using cowdung, urea and pellet feed are shown in the Fig. 14. Feed contributes over 250000 tons of nitrogen in fish ponds. Inorganic $\mathrm{N}$ application in semi intensive fishpond is $28 \mathrm{~kg}$ $\mathrm{N}$ ha/week which enhance the phytoplankton production in pond environment and ultimately increase fish production. Nitrogen loss from aquaculture ponds is very high and it is a great concern for the world community. About 10$30 \%$ of the applied nutrients are utilized by fish and remaining $70-90 \%$ is lost. It is found in semi-intensive tilapia pond that fish utilizes only 9-22\% of the applied $\mathrm{N}$ from different organic and inorganic sources (Table 5). Research findings revealed that in carp polyculture systems, about $40-50 \mathrm{~kg}$ organic manures are needed to produce $1 \mathrm{~kg}$ of fresh fish (NACA, 1989). The food conversion ratio (FCR) in semiintensive and intensive tilapia production systems varies between $0.75-2.5$, thus the production of 100 tons of fish biomass requires $75-250$ tons of feed.

Culture of pangasius and other catfi sh are widespread in Bangladesh which accounted for about $15 \%$ of total fish production in 2012-2013 (DoF, 2014). It is reported that pangasius farming in Bangladesh is characterized by high stocking densities where intensive supply of pelleted feeds is a must to get higher yields (Ali et al., 2013). A large amount of uneaten feeds accumulated in pangasius ponds which contains high levels nitrogen, phosphorous and organic carbon. Nitrogen loss from commercial pellet feed under pangasius pond culture system was recorded 30\% (Fig. 15). Many researchers reported that in pangasius and other fish farming only 10 to $30 \%$ of the applied nutrients using organic and inorganic fertilizers and palette feeds are utilized by fish and remaining 70 to $90 \%$ will be dispersed in the environment and appeared as a potential source of pollution (Rahman et al., 2004; Anh et al., 2010).

\section{Livestock and poultry in Bangladesh: Manure \& $\mathbf{N}$ production}

Livestock is one of the vital agricultural sectors of the rural economy in Bangladesh. Dairy farming is one of the major components of animal agriculture in the country which is the predominant source of income generation (Saadullah, 2001). It accounts for about $14.08 \%$ of agricultural GDP and $2.6 \%$ to the country's GDP and contributes to the rural livelihoods of many small scale farmers through employment opportunities, income generation and food \& nutrition supply (BES, 2009; DLS 2013).

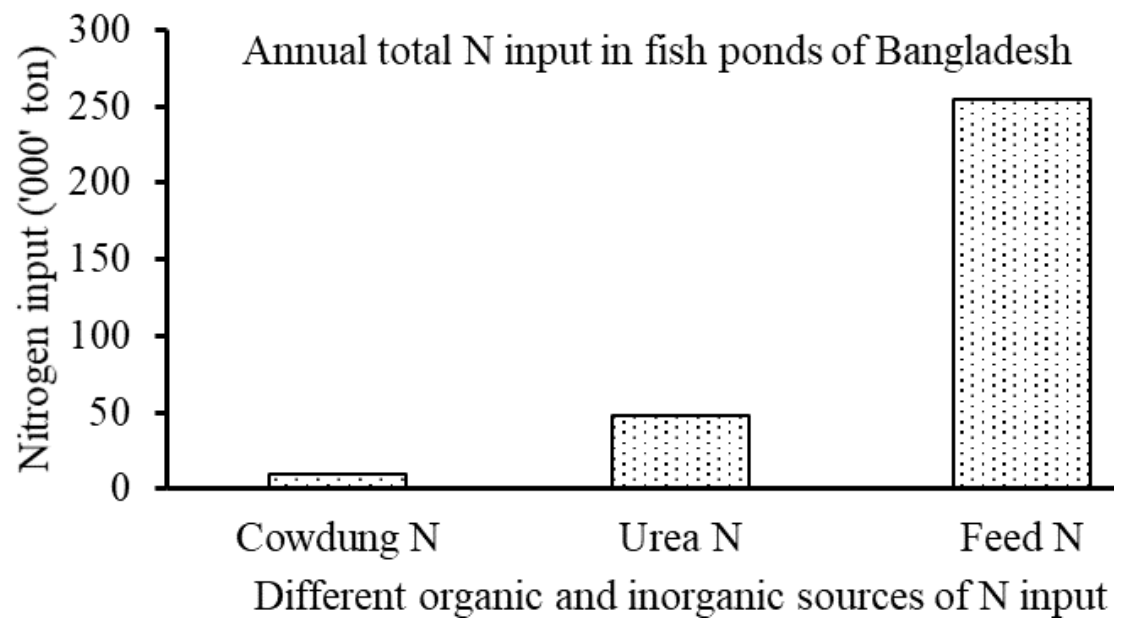

Figure 14. Annual $\mathrm{N}$ inputs in fishponds of Bangladesh (Hasan et al., 2007; Cow dung $\mathrm{N}=1.2 \%$; feed $\mathrm{N}=4.8 \%$ ) 


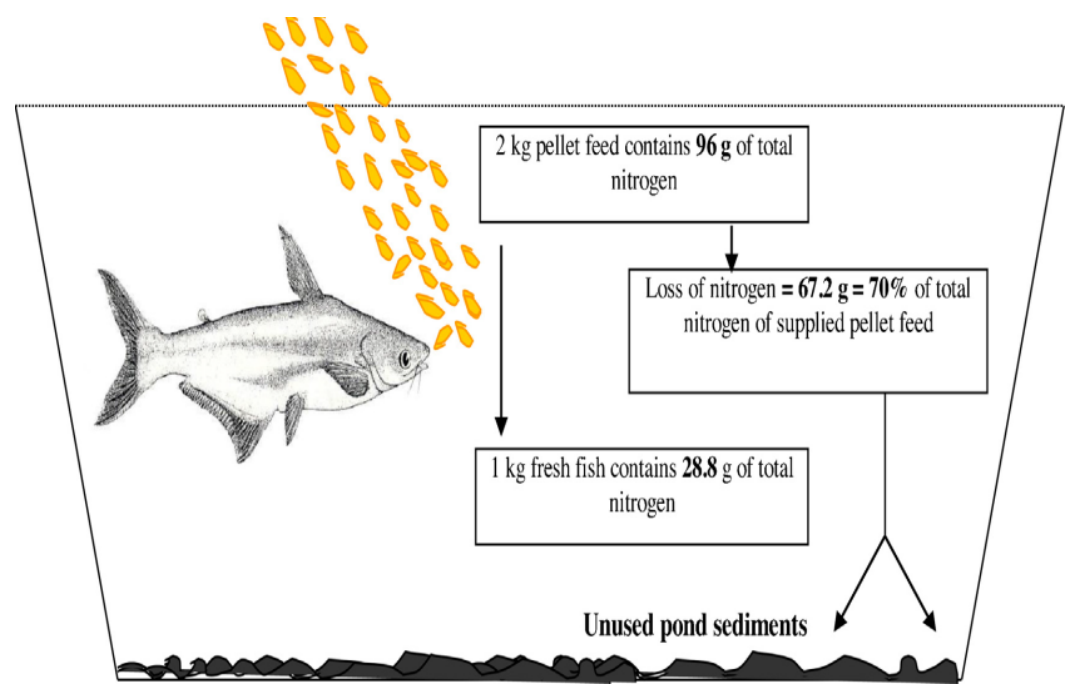

Figure 15. Loss of nitrogen from commercial pellet feed under culture conditions in pangasius ponds (adapted from Rahman, 2004), RE=30\%

Table 6. Number of registered dairy farms, goat farms and self-employment records in private sectors

\begin{tabular}{lcccc}
\hline Year & \multicolumn{2}{c}{ Dairy Farm } & \multicolumn{2}{c}{ Goat Farm } \\
\cline { 2 - 5 } & Number & Self Employment & Number & Self Employment \\
\hline $1979-1980$ & 227 & 2270 & - & - \\
$1997-1998$ & 29,600 & 296,000 & 20,900 & 104,200 \\
$2000-2001$ & 32,600 & 326,000 & 24,900 & 125,000 \\
$2004-2005$ & 52,000 & 520,000 & 26,000 & 130,000 \\
$2009-2010$ & 79,900 & 985,000 & 56,200 & 281,000 \\
\hline
\end{tabular}

Source: DLS (2011)

Table 7. Availability of livestock resources (million) in Bangladesh (1949-2011)

\begin{tabular}{llllllll}
\hline & 1949 & 1960 & 1977 & 1984 & 1996 & 2008 & 2011 \\
\hline Livestock resources & 1949 & 1960 & 1977 & 1984 & 1996 & 2008 & 2011 \\
\hline $\begin{array}{l}\text { Bovine } \\
\text { (cattle/buffaloes/horses) }\end{array}$ & 16.37 & 21.105 & 20.58 & 22.06 & 22.29 & 26.22 & 25.80 \\
$\begin{array}{l}\text { Sheeps/goats } \\
\text { Poultry (fowls and ducks) }\end{array}$ & 25.27 & 6.14 & 9.155 & 14.22 & 14.61 & 17.62 & 17.32 \\
\hline
\end{tabular}

BBS, 2012; Rahman et al., 2014

Majority of the dairy cattle farms in Bangladesh are private and few are government. Number of dairy cattle and goat farms and self-employment records in the private sector showed huge prospect in agriculture (Table 6). The Table 7 showed the number of different categories of livestock in Bangladesh (BBS, 2012; Rahman et al., 2014). The shares of dairy, meat, egg, hides and skin and others as animal farming to GDP were found 18.6, 56.3, 19.8, 2.68 and 2.64\%, respectively (BBS, 2011).

For the quality production of dairy milk and meat quality fodder and nutrient supply must be 
ensured. Numerous studies have reported undoubtedly the severity of animal feed and nutrient deficit in Bangladesh (Table 8). The roughage dry matter (DM) produced surpluses its demand by $3.77 \%$, but losses and otherwise uses result in production deficit of $44.5 \%$ (Table 8). However, an average $56.2 \%$ shortfall of roughage DM and $80.0 \%$ of concentrate DM revealed that better management options i.e. application of balanced fertilizers including nitrogen are required for overcoming the shortfall of fodder production (Huque and Sarker, 2014). Urea is used for fodder and feed production, while liquid $\mathrm{N}$ is used for preservation of semen. Urea is also used in cultivation of fodder crops e.g. napier, maize, alfalfa and Moringaoliefera. However, rates of fertilizer application in fodder crops in most of the cases are lacking and even some cases are found but almost ignored during application. Animals are fed using not only these fodder crops, about 27.32 million tons fibrous biomass and 14530 tons oilcakes are also available as animal feed (BBS, 2012). Use of molasses with straw increases the quality of straw which in turns reduces $30 \%$ methane production by the ruminants (Haque and Chowdhury, 1997). However, from all these activities a significant amount of reactive nitrogen is spreading in the environment which is a matter of great concern and requires proper investigation.

The annual dairy cattle manure production per farms in Bangladesh varies with farm sizes (Table 9). It was estimated that annually a medium dairy farm under rural, periurban and structured market produces 23, 70 and 30 tons of manure, respectively. Manure accumulation is more with marginal and landless farmers. Annual fresh manure production from ruminants is 151.3 million tons and from poultry is 4.52 million tons (Table 10). Total annual manure production may contribute 295913 tons of $\mathrm{N}$; where the share of ruminants and poultry were 234515 and 61398 tons, respectively. Because of chemical and microbial transformation animal manure and urine substantially contribute in reactive $\mathrm{N}$ formation especially in the form of ammonia which enter the hydrological system through leaching and runoff and also partly release to the atmosphere through ammonia volatilization and dentrification (Erisman et al., 2015).

Livestock manure traditionally considered as waste material in Bangladesh that can potentially pollute the environment and may appear as a serious threat to our health. A huge amount of manure is managed traditionally by the small holders as fuel, while medium and large farmers accumulate manure in open pits and apply manure in the crop fields after few months. According to the Inter-Governmental Panel on Climate Change the existing manure management comprised solid waste $(56.2 \%)$, liquid slurry $(1.65 \%)$, burned fuel $(37.3 \%)$ and anaerobic digestion (4.8\%) which clearly revealed poor management of manure in Bangladesh (IPPC, 2006).

Table 8. Demand, production and availability of DM of feeds and fodder for the ruminant animal of Bangladesh in 2011

\begin{tabular}{lccc}
\hline Items & \multicolumn{2}{c}{ Dry matter (DM) of animal feeds (million kg DM) } \\
\cline { 2 - 4 } & Total & Roughage & Concentrate \\
\hline Demand & 73800 & 49200 & 24608 \\
Production & 56081 & 51056 & 5189.7 \\
Availability & 32341 & 27316 & 5025.4 \\
Deficit (\% demand) & 24.0 & 3.77 (surplus) & 79.0 \\
based on production & & & 80.0 \\
Deficit (\% demand) & 56.18 & 44.48 & \\
based on availability & & &
\end{tabular}

Source: Huque and Sarker, 2014 
Table 9. Accumulation of manure in agricultural lands from dairy farms

\begin{tabular}{lccccc}
\hline Types of dairy & \multicolumn{5}{c}{ Manure accumulation (t/ha/yr) } \\
\cline { 2 - 6 } & Landless & Marginal & Small & Medium & Large \\
\hline Rural & 144 & 83 & 33 & 23 & 8 \\
Periurban & 789 & 120 & 59 & 70 & 9 \\
Structured & 475 & 107 & 66 & 30 & 26 \\
\hline
\end{tabular}

Source: ILMM, 2015

Table 10. Annual $N$ production from livestock \& poultry

\begin{tabular}{lccc}
\hline Animals & Manure (million ton) & Nitrogen ('000' t) & Urea Eq. fertilizer ('000' t) \\
\hline Ruminants & 151.3 & 234.52 & 521.14 \\
Poultry & 4.52 & 61.40 & 136.44 \\
\hline
\end{tabular}

Source: ILMM, 2015

Table11. Estimated production of biogas, energy \& bioslurry from animal manure in Bangladesh (BBDF, 2015)

\begin{tabular}{lccc}
\hline Farm animals & \multicolumn{3}{c}{ Annual products } \\
\cline { 2 - 4 } & Biogas $(\mathrm{m} 3)$ & Energy $(\mathrm{MWH})$ & Bioslurry (Million ton) \\
\hline Large ruminants & 68879880 & 151536 & 109 \\
Small ruminants & 4815263 & 10594 & 9 \\
Poultry & 3663106 & 8058.8 & 3.81 \\
Total & 77358249 & 170188.8 & 121.81 \\
\hline
\end{tabular}

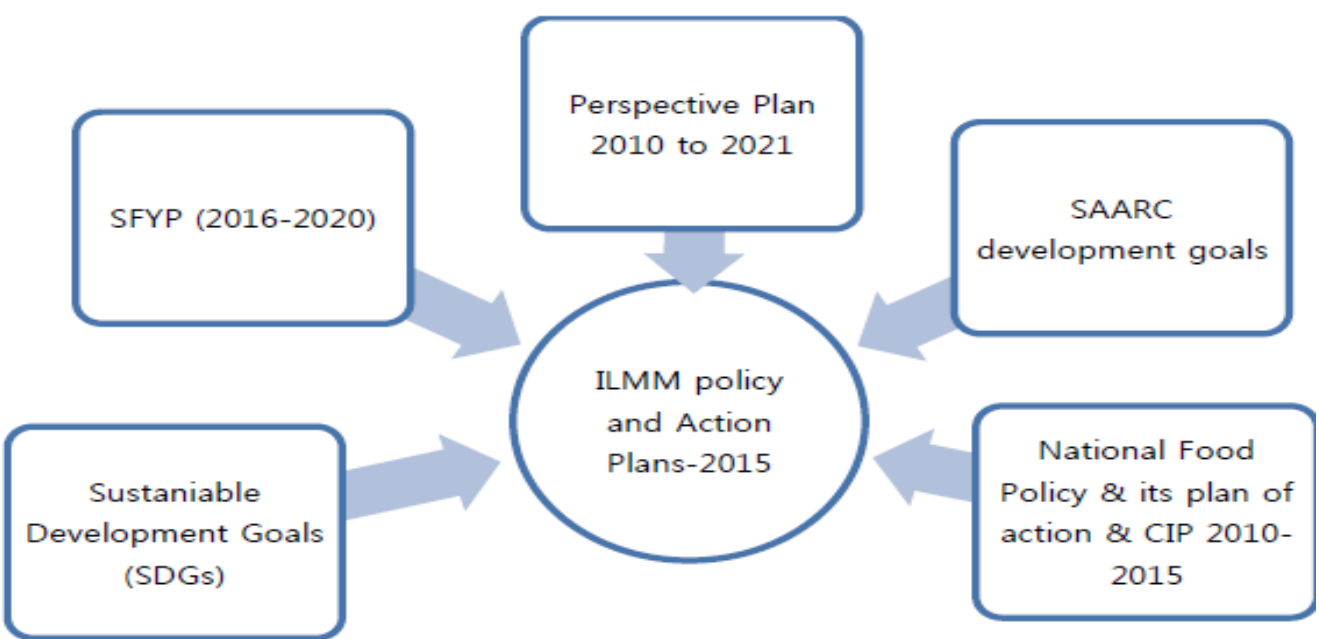

Figure 16. Integrated livestock manure management policy \& action plan (ILMM, 2015) $\left(\mathrm{SFYP}=7^{\text {th }}\right.$ Five Year Plan, CIP $=$ Country Investment Plan, SAARC $=$ South Asia Association for Regional Cooperation) 
Such types of manure management activities might create eutrophication of surface water, enhance leaching of nitrates, build up excess nutrients and heavy metals in soil, contaminate soil and water resources, and release ammonia, methane and other gases to the atmosphere. Improved management of manure might help in the reduction of such problems and environmental pollution. Anaerobic digestion and production of biogas can be considered as one of the improved manure management technologies which reduce solid storage and burning of manure and decrease carbon monoxide and particulate matter emission. According to Bangladesh Biogas Development Foundation (BBDF) the available manure in the country can produce 77.4 million $\mathrm{m}^{3}$ of biogas, $170 \times 10^{3} \mathrm{MWH}$ of power and 121.8 million ton of bioslurry annually (Table 11). However, in most of the cases produced bioslurry is left at open spaces which promote environmental pollution.

The Government of Bangladesh has launched an Integrated Livestock Manure Management (ILMM) policy and action plan in 2015 which might solve the problems associated with manure management in farmers' levels (Fig. 16). The ILMM policy sets out the objectives, strategies and approaches to advance anaerobic digestion of manure and generate new energy, produce organic fertilizer and/or soil conditioner, vermicompost, organic pesticides, reduce air pollution, reduce threats to public health, and make livestock production system sustainable. The ILMM (2015) is a draft policy and action plan which will be implemented during 15 years (2016-2030) time periods. The ILMM focuses on five themes along with sets of programs under each theme for sustainable development of livestock resources in Bangladesh. Five themes are sustainable livestock \& manure management for socioeconomic gain accompanied by reduction of pollution, mitigation of public health threats, institutional strengthening and capacity enhancement, extension, research and development, and awareness creation on ILMM. It is apprehended that finalization and strict adoption of ILMM resolves the anomalies and threats associated with manure collection and management which further provides the strategic scope for proper investigation of reactive nitrogen dynamics in the environment.

\section{Conclusions}

A comprehensive review has been accomplished on use and management of urea fertilizer in crop, fishery and livestock sectors of Bangladesh. At present about 2.45 million tons of urea fertilizer is used in crop fields, while the projected urea requirement in 2050 will be 3.92 million tons. Though there is lacking of information on the exact amount of urea use in fishery and livestock sectors, however, the quantity is huge. Because of low recovery efficiency of nitrogen, a large amount remains unutilized which is a hotspot of reactive nitrogen and potential source for soil, water and atmospheric pollution. Fishpond sludge, livestock manure and industrial effluents contain significant amount of reactive $\mathrm{N}$ which otherwise degrades, disintegrates and collapses the ecosystem functions if proper attention is not given to convert these wastes into value added product and recycle in agriculture. The study might help policy makers to understand the nitrogen management scenarios in agriculture and its possible dynamics in the environment and thus to develop guidelines or become strict to adopt already developed rules and regulations for long-term agricultural and environmental sustainability.

\section{Acknowledgements}

We collected information and data from different published literatures and collated in this paper. Therefore, we earnestly acknowledge their scholastic contributions and remain ever grateful to them.

\section{References}

Ali, H., Haque, M. M. and Belton, B. 2013. Striped catfish (Pangasianodon hypophthalmus, Sauvage, 
aquaculture in Bangladesh: an overview. Aquaculture Research, 44: 950-965.

AIS, 2016. Agriculture Information Services. Department of Agriculture Extension, Ministry of Agriculture, Government of Bangladesh.

Anh, P.T., Kroeze, C., Bush, S.R., Mol, A.P.J. 2010. Water pollution by Pangasius production in the Mekong Delta, Vietnam: causes and options for control. Aquaculture Research, 42: 108-128.

Bangladesh Unnayan Onneshan. Future Fertiliser Demand for Sustaining Rice production in Bangladesh: A Quantitative Analysis. Unnayan Onneshan-The Innovators 16/2, Indira Road, Farmgate, Dhaka - 1215, Bangladesh.

http://www.unnayan.org/reports/Livelihoo d/future_fertilizer_demand.pdf (Retrieved on April 15, 2018).

BBS (Bangladesh Bureau of Statistics). 1980. Statistical Year Book of Bangladesh, Statistics Division, Ministry of Planning, The Government of peoples Republic of Bangladesh.

BBS (Bangladesh Bureau of Statistics). 2011. Statistical Year Book of Bangladesh, Statistics Division, Ministry of Planning, The Government of peoples Republic of Bangladesh.

BBS (Bangladesh Bureau of Statistics). 2012. Statistical Year Book of Bangladesh, Statistics Division, Ministry of Planning, The Government of peoples Republic of Bangladesh.

BBS (Bangladesh Bureau of Statistics). 2015. Statistical Year Book of Bangladesh, Statistics Division, Ministry of Planning, The Government of peoples Republic of Bangladesh.

BBS (Bangladesh Bureau of Statistics). 2016. Statistical Year Book of Bangladesh, Statistics Division, Ministry of Planning, The Government of peoples Republic of Bangladesh.
Begum, R. A., Zaman, M. W., Mondol, A. T. M. A. I., Islam, M. S. and Hossain, K. M. F. 2011. Effects of textile industrial waste water and uptake of nutrients on the yield of rice. Bangladesh J. Agril. Res., 36(2): 319-331.

Belton, B., Karim, M., Thilsted, S., Murshed-EJahan, K., Collis, W. and Phillips, M. 2011. Review of aquaculture and fish consumption in Bangladesh. Studies and Reviews 2011-53. The World Fish Center.

BES (Bangladesh Economic Survey) 2009. Department of Finance, Ministry of Finance and Planning, Government of the People's Republic of Bangladesh. Dhaka. pp 71.

BFA (Bangladesh Fertilizer Association). 2018. Al-Razi Complex (5th Floor), 166-167, Shaheed Syed Nazrul Islam Sarani, Purana Paltan, Dhaka 1000, Bangladesh.

Chowdhury, M., Mostafa, M. G., Biswas, T.K., Mandal, A. and Saha, A.K. 2015. Characterization of the Effluents from Leather Processing Industries. Environmental Process, 2:173-187. DOI 10.1007/s40710-015-0065-7.

DLS, 2013. Annual Report on Livestock, Division of Livestock Statistics, Ministry of Fisheries and Livestock, Farmgate, Dhaka, Bangladesh.

Department of Livestock Services, 2005. Annual Report. Ministry of Fisheries and Livestock, Government of Bangladesh. Dhaka, Bangladesh.

Dey, S. and Islam, A. 2015. A Review on Textile Wastewater Characterization in Bangladesh. Resources and Environment, 5(1): 15-44. DOI: $10.5923 /$ j.re. 20150501.03

DLS. 2011. Annual Report on Livestock, Division of Livestock Statistics, Ministry of Fisheries and Livestock, Farmgate, Dhaka, Bangladesh. 
DoF. 2014. Fisheries Statistical Yearbook of Bangladesh 2012-13. Fisheries Resource Survey System (FRSS). Department of Fisheries, Dhaka, Bangladesh, pp. 52.

DOF. 2010. Fisheries Statistical Year Book of Bangladesh 2008-2009. Volume 26, No. 1. Fisheries Resource Survey System, Department of Fisheries, Ministry of Fisheries and Livestock.

Erisman, J.W., Galloway, J.N., Dies, N.B. Sutton, M.A., Bleeker, A., Grizzetti, B., Leach, A.M. and de Vries, W. 2015. Nitrogen: too much of a vital resource. Science Brief. WWF, Netherlands, Zeist, The Netherlands.

Erisman, J.W., Galloway, J.N., Seitzinger, S., Bleeker, A. and Butterbach-Bahl, K. 2011. Reactive nitrogen in the environment and its effect on climate change. Current Opinion in the Environmental Sustainability, 3(5): 281290.

Erisman, J. W. and Sutton, M. A. 2008. Reduced nitrogen in ecology and the environment, Environmental Pollution, 154: 357-507.

Eruola, A.O., Ufoegbune, G.C., Eruola, A.O., Awomeso, J.A., Adeofun, C.O., Idowu, O.A., et al. 2011. An assessment of the effect of industrial pollution on Ibese River, Lagos, Nigeria. African Journal of Environmental Science andTechnology, 5 (8): 608-615.

FAO, 2014a. Fishery and Aquaculture Country Profiles, The People's Republic of Bangladesh. FAO Fishery and Aquaculture Department, Food and Agriculture Organization of the United Nations, Rome, Italy. http://www.fao.org/fishery/facp/BGD/en

FAO, 2014b. The state of world fi sheries and aquaculture. Food and Agriculture Organization of the United Nations, Rome, Italy, p. 223.

FAO, 2015. World Fertilizer Trends and Outlook to 2018. Food and Agriculture
Organization of the United Nations, Rome Italy.

FRG, 2012. Fertilizer Recommendation Guide (FRG). Bangladesh Agricultural Research Council (BARC), Farmgate, Dhaka 1215. $274 \mathrm{p}$.

Gaihre, Y.K., Singh, U., Islam, S.M.M., Huda, A., Islam, M.R., Sanabria, J., Satter, M.A., Islam, M.R., Biswas, J.C., Jahiruddin, M. and Jahan, M.S. 2018. Nitrous oxide and nitric oxide emissions and nitrogen use efficiency as affected by nitrogen placement in lowland rice fields. Nutrient Cycling in Agroecosystems, DOI: 10.1007/s10705-017-9897-z.

Galloway, J.N., Dentener, F. J., Capone, D. G., Boyer, E. W., Howarth, R. W., Seitzinger, S. P., Asner, G. P., Cleveland, C. C., Green, P. A., Holland, E. A., Karl, D. M., Michaels, A. F., Porter, J. H. ,Townsend, A. R. and Voosmarty, C. J. 2004. Nitrogen Cycles: Past, Present and Future. Biogeochemistry, 70: 153-226.

Guha, A.K. 2011. Environmentally Friendly Techniques in Textiles. CTA-2010.

Hasan, M.R., Hecht, T., De Silva, S.S., Tacon, A.G.J. 2007. Study and analysis of feeds and fertilizers for sustainable aquaculture development. FAO Fisheries Technical Paper. No. 497.Rome, FAO. 510p.

Hossain, M.A., Uddin, M.K., Molla, A.H., Afrad, M.S.I., Rahman, M.M., Rahman, G.K.M.M. 2010. Impact of industrial effluents discharges on degradation of natural resources and threat tofood security. The Agriculturists, 8 (2): 80-87.

Huque, K.S. and Sarker, N.R. 2014. Feeds and feeding of livestock in Bangladesh: performance, constraints and options forward.Bangladesh Journal of Animal Science, $43 \quad$ (1): $\quad 1$ 10.DOI: http://dx.doi.org/10.3329/bjas.v4 3i1.19378

Islam, M.S., Uddin, M.K., Tareq, S. M., Shammi, M., Kamal, A.K.I., Sugano, T., 
Kurasaki, M., Saito, T., Tanaka, S. and Kuramitz, H. 2015. Alteration of Water Pollution Level with the Seasonal Changes in Mean Daily Discharge in Three Main Rivers around Dhaka City, Bangladesh. Environments, 2: 280294.doi: 10.3390/environments2030280

ILMM. 2015. Draft National Integrated Livestock Manure Management (ILMM) Policy. Government of the People's Republic of Bangladesh Ministry of Fisheries and Livestock. Bangladesh Secretariat, Dhaka.

Islam, S.M.M.,Gaihre, Y.K., Biswas, J.C.,Jahan, M.S., Singh, U.,Adhikary, S.K.,Satter, M.A. andSaleque, M.A. 2018. Different nitrogen rates and methods of application for dry season rice cultivation with alternate wetting and drying irrigation: Fate of nitrogen and grain yield. Agricultural Water Management, 196: 144-153.

Kafiluddin, A. 2008. Fertilizer distribution, subsidy, marketing, promotion and agronomic use efficiency scenario in Bangladesh. IFA Crossroads Asia-Pacific 2008 in Melbourne, Australia.

Lu, C. and Tian, H. 2013. Net greenhouse gas balance in response to nitrogen enrichment: perspectives from a coupled biogeochemical model. Global Change Biology, 19: 571-588.

Lu, C. and Tian, H. 2017. Global nitrogen and phosphorus fertilizer use for agriculture production in the past half century: shifted hot spots and nutrient imbalance.Earth System Science Data, 9: 181-192.

Mamun-Ur-Rashid, M., Belton, B., Phillips, M., Rosentrater, K.A. 2013. Improving aquaculture feed in Bangladesh: From feed ingredients to farmer profit to safe consumption. WorldFish, Penang, Malaysia. Working Paper: 2013-34.
NACA. 1989. Integrated fish farming in China. NACA Technical Manual 7. A World Food Day

Publication of the Network of Aquaculture Centres in Asia and the Pacific, Bangkok, Thailand, $278 \mathrm{p}$.

Paul, H. L., Antunes, A. P. M., Covington, A. D., Evans, P. and Phillips, P.S. 2013. Bangladeshi Leather Industry: An Overview of Recent Sustainable Developments. Journal - Society of Leather Technologists and Chemists, 97: 25-32.

Rahman, M.M., Yakupitiyage, A., Ranamukhaarchchi, S.L. 2004. Agricultural use of fish pond sediment for environmental amelioration. Thammassat International Journal of Science and Technology, 9: 1-10.

Rahman, M.M. 2004. Evaluation of Mixed Feeding Schedule with Varying Dietary Protein Content on the Growth Performance and Reduction of Cost of Production for Pangas with Silver Carp. M.S. Thesis. Department of Aquaculture, Bangladesh Agricultural University, Mymensingh, Bangladesh pp. 72.

Rahman, S., Begum, I. A. and Alam, M. J. 2014. Livestock in Bangladesh: distribution, growth, performance and potential. Livestock Research for Rural Development. Volume 26, Article \#173. Retrieved April 9, 2018, from http://www.lrrd.org/lrrd26/10/rahm26173. html

Saadullah, M. 2001. Smallholder Dairy Production and Marketing in Bangladesh. Paper presented at South-South Workshop on Smallholder Dairy Production and Marketing. NDDB-ILBS. 13-16. March. 2001, Ahmedabad, India.

Shah, A.L., Rahman, M.S., and Aziz, M.A. 2008. Outlook for fertilizer consumption and food production in Bangladesh. 
Bangladesh Journal of Agriculture and Environment, 4: 1-8.

Saha, R. 2007. Impact of the Effluents of Textile Dying Industries on the Water Quality of D.N.D. Embankment Area, Narayanganj. (M.S. Thesis). Jahangirnagar University, Bangladesh.

Sarker, N. R., Huque, K. S. and Khaleduzzaman, A. B. M. 2012. Feeds, Fodder and Feeding Challenges for Bangladesh. Paper presented in the Seminar and Reception: Animal Husbandry

Sutton, M. A., Oenema, O., Erisman, J. W., Leip, A., van Grinsven, H., and Winiwarter, W. 2011. Too much of a good thing. Nature, 472: 159-161.

The Daily Observer, 2015. Contribution of agriculture to GDP sliding gradually. http://www.observerbd.com/2015/03/09/7 6925.php (Accessed on April 9, 2018)

Tabriz, S. S., Mojid, M. A. and Wyseure, G. C. L. 2011. Irrigation suitability of North Bengal Sugar Mill's effluent and its impact on soil properties. J. Bangladesh Agril. Univ. 9(2): 283-290.
Tian, H., Xu, X., Liu, M., Ren, W., Zhang, C., Chen, G., and Lu,Ju, X. T., Xing, G. X., Chen, X. P., Zhang, S. L., Zhang, L. J., Liu,X. J., Cui, Z. L., Yin, B., Christie, P., Zhu, Z. L., and Zhang, F.S. 2009. Reducing environmental risk by improving $\mathrm{N}$ management inintensive Chinese agricultural systems, P. Natl. Acad. Sci. USA, 106, 3041-3046.

UNEP and WHRC. 2007. Reactive Nitrogen in the Environment: Too Much or Too Little of a Good Thing. United Nations Environment Programme, Paris.

World Population Review. 2018. http://worldpopulationreview.com/countri es/bangladesh-population/ (Accessed on April 16, 2018)

Wortmann, C.S., Tarkalson, D.D., Shapiro, C.A., Dobermann, A.R., Ferguson, R.B.,Hergert, G.W. and Walters, D. 2011. Nitrogen use efficiency of irrigated corn for three cropping systems in Nebraska. Agronomy Journal, 103: 76-84. doi:10.2134/agronj2010.0189 